\title{
Biogas Production From Co Digestion of Automotive Wastewater And Synthetic Wastewater in Anaerobic Reactor
}

\author{
Uzana Ismail $^{1^{*}}$, Zaifah Che Wil ${ }^{2 *}$, Syazwani Idrus ${ }^{3}$ \\ 1,2 Department of Civil Engineering, \\ Sultan Idris Shah Polytechnic, \\ ${ }^{3}$ Faculty of Engineering, \\ University Putra Malaysia.
}

\begin{abstract}
The purpose of this study is to investigate the biogas potential from automotive wastewater codigested with Synthetic wastewater treated in anaerobic reactor. This experiment was run by continuously mixed with mechanical Agitator stirring tank reactor and were established under mesophilic condition at temperature of $38^{\circ} \mathrm{C}$. The source of inoculum used in this study were obtained from sewage treatment plant. The experiment was analyzed based on COD removal and biogas production in relation with parameters such as pH, organic loading rate, alkalinity and effect of Zinc and Copper which runs on automotive wastewater. From the result obtains, the reactor condition was unstable during mono digestion of automotive wastewater which aligned with indication of decreasing biogas production, low $\mathrm{pH}$ value below 6.0 and low COD removal with value of $63.4 \%$. However, the reactors become stable during co digestion of automotive wastewater with Synthetic wastewater with $0.12 \mathrm{~g} / \mathrm{L} / \mathrm{d}$ OLR and with highest methane production $0.140 \mathrm{~L}$ of $\mathrm{CH}_{4}$ / day. The findings illustrate the nutrient available in Synthetic wastewater could enhance the synergistic effect in co digestion with automotive wastewater and therefore resulted with the highest COD removal rates.
\end{abstract}

Keywords:- Anaerobic co-digestion, chemical oxygen demand, automotive wastewater, heavy metal.

\section{INTRODUCTION}

The major global challenges and issue today was global warming and global energy demand. In order to deal with the increasing demand for energy and at the same time will help to decreasing the negative impact to the world global warming, renewable energy would be the best option in the future (Haw et al., 2006). Biogas can be seen as one of the sensible options towards renewable energy source, which can be used as a replacement to fossil fuels both in power and heat production, and also as gaseous vehicle fuel (Shin et al., 2010). Biogas can be captured and used as a potential energy resource and it is end product through the processes of Anaerobic Digestion (AD). Over the years and throughout the world, $\mathrm{AD}$ appears to be one of technology widely utilized for the treatment of organic waste and wastewater. Wastewater produce automotive industries contains with high organic and inorganic matter. Therefore, proper treatment of automotive wastewater (AWW) has drawn considerably attention before releasing into environment because of their association with various problems of the ground and water resources.

Therefore, the anaerobic digestion process is essential in order to reduce significant environmental impact of industrial wastewater by converting some of the polluting material to methane in a controlled environment. Thus, methane produces by anaerobic co- digestion of industrial wastewater and agricultural waste have many benefits in providing a clean fuel to society and environment. Common method being used during the treatment process of AWW is activated sludge process which integrating an aeration system (Idrus, 2007). During the process of activated sludge, mass of microorganisms (usually Bacteria) is uses to aerobically treat wastewater. The wastewater is thoroughly diffused and circulated with air in an aeration tank, and the organic matter is decay into microbial cell tissue and carbon dioxide. However, implementation of aerobic treatment needs external input of energy to operate the aeration system.

AD has obvious advantages over aerobic process such as it can produce and capture biogas production as a source of energy through the invention of anaerobic digester. Ward et al., (2008) described the sealed environment of the process reduce environmental pollution by preventing the exit of methane process into the atmosphere. One of the key for enhancing performance of anaerobic digestion of organic matter is co-digestion of multiple substrates. Co-digestion of combination of different waste stabilizes the feed to the bioreactor, thereby improving the Carbon to Nitrogen $(\mathrm{C} / \mathrm{N})$ ratio and decreasing the concentration of nitrogen (Hartman \& Ahring, 2005). The aim of this study in the following chapters provides waste converted to energy through codigestion of automotive wastewater with Synthetic wastewater using continuous stirred tank reactor (CSTR). The waste is transformed into a renewable energy source using $\mathrm{AD}$ approach while at the same time will reducing global methane emissions. 


\section{METHODOLOGY}

\section{A. Sample collection and preparation}

\section{Automotive Wastewater Sampling}

The primary substrates used in this study is raw Automotive Wastewater collected from Perusahaan Otomobil Sdn Bhd (Proton), located at Hicom Industrial Estate, Shah Alam, Selangor. Samples were taken by grab sampling from incoming tank of the wastewater treatment plants. After sampling, the samples were stored in large capped container and transport to the laboratory and preserved at $4{ }^{\circ} \mathrm{C}$ as biological activity is significantly reduced and in order to preserve the property of the sample from aspect of physical, chemical and biological and as well as to ensure that the sample represent the actual condition at the study area.

\section{$>$ Preparation of Synthetic Wastewater}

Synthetic wastewater (SWW) will be utilized as a surrogate material as it allowed the use of a complex chemical feedstock of high biodegradability without the risk of exposure to pathogens present in real sewage. This Synthetic wastewater content is essential for optimum anaerobic microbial growth.

\section{Source of Inoculum}

The inoculum used to inoculate the substrate during the experiment as well as an active source of microbes. For the present study, culture used as an inoculum was from wastewater treatment plant at Faculty of Engineering, University of Putra Malaysia. The first part of the work was carried out with sludge sieved to remove any nonbiodegradables material.

\section{B. Feed Composition of Samples used into CSTR.}

In this study, three series of experiments were used to investigate co-digestion of each substrate in single CSTR. CSTR were filled with $2 \mathrm{~L}$ sludge as inoculum and $2 \mathrm{~L}$ of substrates with various combinations. The CSTR were fed once per day for each trial as given in Table 1. After 24 hours of HRT, the digestate at the same amount of feeding were taken and was added back to keep the constant of $4 \mathrm{~L}$ working volume of the reactor.

\begin{tabular}{|c|c|c|c|}
\hline Trial & Process & Sample & $\begin{array}{c}\text { Composition Ratio of (Feedstock (on COD } \\
\text { Basis) }\end{array}$ \\
\hline 1 st & Acclimatization Period & SWW & $100: 0$ \\
\hline 2nd & $\begin{array}{c}\text { Adaptation to Mono Digestion of } \\
\text { AWW }\end{array}$ & AWW & $100: 0$ \\
\hline \multirow{2}{*}{$3 \mathrm{rd}$} & $\begin{array}{c}\text { Adaptation to Co Digestion of } \\
\text { SWW+AWW }\end{array}$ & $\begin{array}{c}\text { SWW } \\
+ \\
\text { AWW }\end{array}$ & $\begin{array}{c}\text { SWW: AWW } \\
80: 20\end{array}$ \\
\hline \multirow{2}{*}{4 th } & $\begin{array}{c}\text { Adaptation to Co Digestion of } \\
\text { RSL+AWW }\end{array}$ & $\begin{array}{c}\text { RSL } \\
+ \\
\text { AWW }\end{array}$ & $\begin{array}{c}\text { RSL: AWW } \\
80: 20\end{array}$ \\
\hline
\end{tabular}

Table 1:- Feed compositions of sample use in CSTR.

\section{Type of Digester and Operation}

Type of digester in a laboratory scale will be employ in this research is continuous stirred tank reactor (CSTR) with a total volume of 5 liters and 3 liters working volume and was built from graduated jacketed borosilicate glass reactor. The CSTR equipped with stainless steel top cover supported with feed tube and biogas tube along with cone bearing seal (anti-leak gas). The reactors had stirrer set using digital overhead stirrer motor provided with adjustable speed. The CSTR reactor were seeded with sludge (inoculum) and then acclimated to Synthetic wastewater until steady state which is a condition of constant production of gas was achieved. Once the digester is ready, it was used for the anaerobic codigestion. The digester will be running for the period of 42 days including acclimatization period and were controlled at mesophilic conditions with temperature of $35 \mathrm{oC}$ by circulating hot water from water bath tank into the water jacketed of reactor. The CSTR were continuously mixed with mechanical agitator at $300 \mathrm{rpm}$. The mixing was control by timer and the mixing process will ensure the homogeneity of the inoculum and the substrates.

\section{Analytical Method}

The digestate characteristic produce from CSTR were evaluated in laboratory such as COD, and $\mathrm{pH}$ right after the setup stage has been done. Biogas volume samples are measured daily by using water displacement method whereas the percentage of methane by using gas chromatography. The percentage of biogas was captured by using Tedlar bag with 1.6 litres capacity.

\section{RESULTS AND DISCUSSIONS}

The correlations experimental results and data analysis with respect to $\mathrm{pH}$ value, organic loading rate (OLR), chemical oxygen demand (COD) removal, alkalinity and biogas production of mono digestion and co digestion of Automotive wastewater (AWW) and Synthetic wastewater (SWW) were presented and discussed. Five different phases of experiments were employed as shown in Table 2 below. 
ISSN No:-2456-2165

\begin{tabular}{|c|c|c|c|c|c|c|}
\hline Time (days) & Phase & Process & Feedstock & Feeding Ratio & $\begin{array}{c}\text { OLR } \\
\text { (g/L/day) }\end{array}$ & $\begin{array}{c}\text { Concentration } \\
(\mathrm{g} \text { COD } / \mathrm{L})\end{array}$ \\
\hline 1 & 1 & \multirow{3}{*}{ Adaptation Period } & \multirow{3}{*}{ Synthetic wastewater } & \multirow[t]{3}{*}{ 100:0 } & 0.25 & 0.50 \\
\hline $5-11$ & 2 & & & & 0.40 & 0.80 \\
\hline $12-17$ & 3 & & & & 0.12 & 0.23 \\
\hline $18-29$ & 4 & Mono-Digestion & $\begin{array}{l}\text { Automotive } \\
\text { Wastewater }\end{array}$ & 100:0 & 0.12 & 0.23 \\
\hline $30-42$ & 5 & Co-Digestion & $\begin{array}{c}\text { Automotive } \\
\text { Wastewater }+ \\
\text { Synthetic wastewater }\end{array}$ & $20: 80$ & 0.12 & 0.23 \\
\hline
\end{tabular}

Table 2:- Reactor operating conditions during experimental work.

\section{A. Organic Loading Rate (OLR)}

The organic loading rates used during the lab experiment are shown in Figure 1. First, during the adaptation period namely phase 1 to phase 3 , the initial of OLR used to acclimate the microbes to operating condition were $0.25 \mathrm{~g} / \mathrm{L} / \mathrm{d}$. The first start up initial were run for several days and then continued with increased of OLR to $0.4 \mathrm{~g} / \mathrm{L} / \mathrm{d}$ until day 11 . However, at OLR $0.4 \mathrm{~g} / \mathrm{L} / \mathrm{d}$ the reactor was disturbed due to excess loading of substrates which was indicates by fluctuation of $\mathrm{pH}$ and COD removal rate.

On the following day, the reactor was fed with OLR $0.12 \mathrm{~g} / \mathrm{L} / \mathrm{d}$ with feedstock concentration of $0.23 \mathrm{COD} / \mathrm{L} / \mathrm{d}$. The final OLR was chosen as the optimum working value based on the initial concentration of primary feedstock in this experiment which runs on AWW. Stability of the reactor system was monitored through the COD removal produced. The reactors become stable at the $0.12 \mathrm{~g} / \mathrm{L} / \mathrm{d}$ OLR and were kept under the operating conditions on day 13 till the end of experiments on day 42.

\section{B. Effect of pH Value.}

Figure 2 shows the behaviour of $\mathrm{pH}$ and time measured in CSTR during anaerobic digestion process. Summarized experiments result of $\mathrm{pH}$ value were depicts in the Table 3 below. Literally, $\mathrm{pH}$ in the system during the experiment ranged between $\mathrm{pH} 5.7$ to 6.7. At the beginning stage of the adaptation process, the reactor was fed with Synthetic wastewater which is started from Phase 1 to 3 for a period of two weeks.

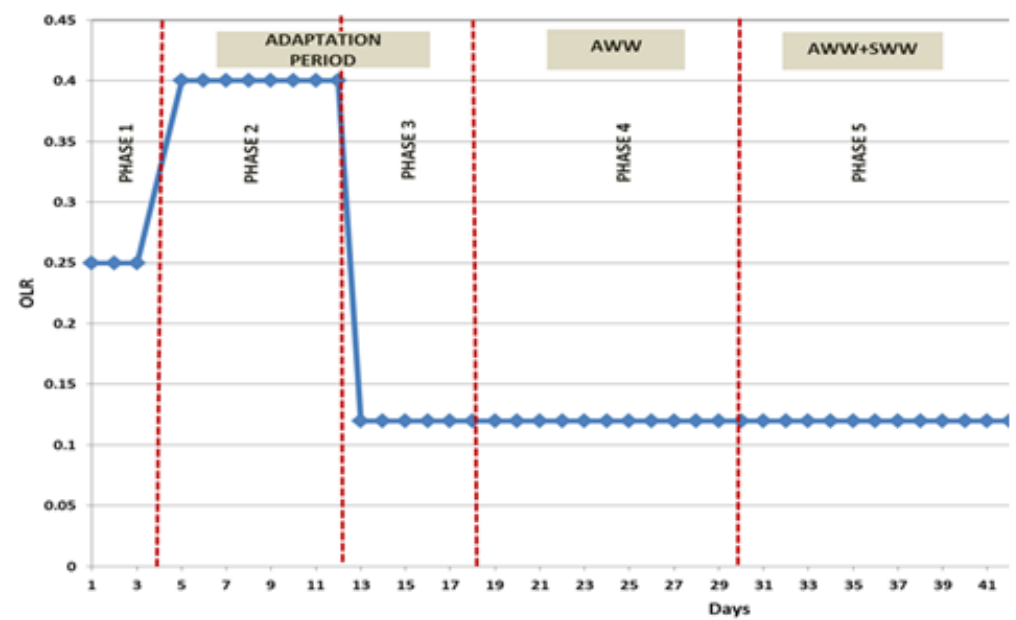

Fig 1:- Organic loading rate of the reactor.

\begin{tabular}{|c|c|c|c|}
\hline \multirow{2}{*}{$\mathbf{p H}$} & Adaptation Period & Single Digestion of AWW & Co-Digestion of SWW + AWW \\
\hline Min & 5.92 & 5.75 & 6.32 \\
\hline Max & 6.52 & 6.7 & 6.73 \\
\hline Average & 6.22 & 6.17 & 6.50 \\
\hline
\end{tabular}

Table 3:- Experiments results of $\mathrm{pH}$ during operation of CSTR.

At the beginning stage of the adaptation process, the reactor was fed with Synthetic wastewater which is started from Phase 1 to 3 for a period of two weeks. According to the Figure 2, $\mathrm{pH}$ distribution at the beginning of the process was around 6.3. Then the $\mathrm{pH}$ started to fluctuate from $\mathrm{pH}$ range 6.54 to 5.92 even though the OLR value is continuously constant from day 4 till day 11 . The fluctuating in $\mathrm{pH}$ indicates that the reactor was in shock condition and worked under unstable condition value most probably due to accumulation of fatty acids caused by increased of OLR fed from $0.25 \mathrm{~g} / \mathrm{L} / \mathrm{d}$ to $0.4 \mathrm{~g} / \mathrm{L} / \mathrm{d}$ into the reactor as agreed by Ahring et al., (1995). After that, the reactor was fed with lower OLR value of $0.12 \mathrm{~g} / \mathrm{L} / \mathrm{d}$ and the system recover itself with the $\mathrm{pH}$ value gradually rise at an average value of 6.22 
in Phase 3. Thus, this indicates that the reactor has high buffer capacity and operated under stable condition.

However, after the addition of AWW in the reactor on day 18 onwards until day $29, \mathrm{pH}$ started to be fluctuated and rapidly decreased and finally dropped to 5.85 during the digestion (absolute minimum 6). The dropped of $\mathrm{pH}$ indicating that the system operating at unstable conditions (Strik, 2005). In the next following occasions during the co digestion period of SWW and AWW namely Phase 5, the $\mathrm{pH}$ value was observed to be fluctuated at the beginning process before it was started to drop again and stable to be less or almost less than 6.32 with an average $\mathrm{pH}$ of 6.50 . The results showed that the $\mathrm{pH}$ stability of the reactor was improved comparing to digestion of AWW alone. In the next phase, SWW was reintroduced as feeding material into the reactor. The results showed that the stability of the reactor increased with $\mathrm{pH}$ value in the range of 6.5 .

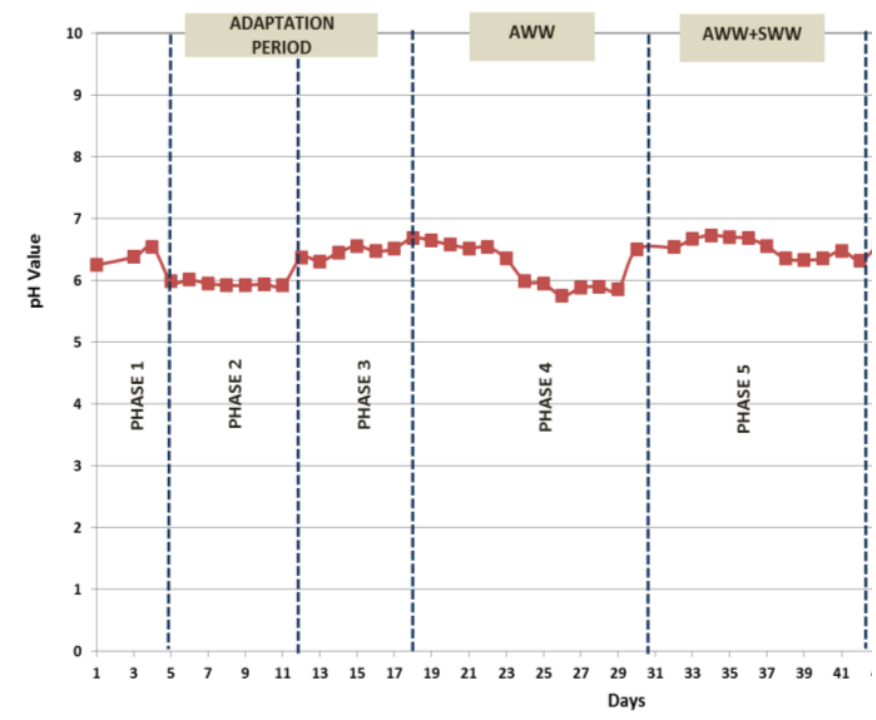

Fig 2:- Behavior of $\mathrm{pH}$ in the reactor digesting different feedstock

\section{Chemical Oxygen Demand (COD) Removal.}

Table 4 shows the COD removal during the CSTR operation. At the beginning stage of the experiments, COD removals in the reactor showed to be fluctuated indicating that the microbes present in the sludge were still adapted to the given feedstock. However, when lower OLR had been used to the system, average COD removal around 91.6\% were observed. Hence, the decreasing of OLR from $0.4 \mathrm{~g}$ $\mathrm{COD} / \mathrm{L}$ to $0.12 \mathrm{~g} \mathrm{COD} / \mathrm{L}$ had resulted to higher percentage of COD removal which is showed that the decreasing of OLR would enhance the performance of microbes to consume the organic matter in the given feedstock. In phase 4, COD removal efficiency decreased from $96 \%$ to $65.20 \%$ as the new feeding material from SWW to AWW was introduced into the reactor. The mono digestion of AWW is composed of inorganic materials which include heavy metal thus caused slow ability to biodegrade and take longer time to break down before being converted to methane. This may describe with the trend of COD removal during this phase was fluctuated from day 18 to day 29 with average removal during the digestion was $64 \%$.

In Phase 5, feeding material in reactor has changed to co-digestion of SWW and AWW. At the beginning of the co-digestion the COD removal decreased and fluctuated in the range of $65 \%$ to $70 \%$. However, the COD removals become stable and increased gradually for the rest of the day indicating that the microbes have been adapted to the given feedstock. The highest COD removal being recorded was on day 42 with value of $88 \%$ and the reactor achieved steady state at $86.6 \%$ of COD removal. Hence, the co-digestion of SWW and AWW could improve the ability of COD removal in the reactor. In other hand, co-digestion process can provide not only the necessary microorganisms but also the appropriate balance of nutrients to create favorable conditions for the methanogens to thrive (Mussoline, 2013). These results suggested that co digestion of this feedstock were possible.

\begin{tabular}{|c|c|c|c|c|}
\hline \multirow{2}{*}{$\mathbf{p H}$} & Time (days) & $\begin{array}{c}\text { Initial } \\
\text { CODadded } \\
\text { (g COD/L) }\end{array}$ & $\begin{array}{c}\text { Average CODremoved } \\
\text { (g COD/L) }\end{array}$ & $\begin{array}{c}\text { Average COD Removal } \\
\text { Rate (\%) }\end{array}$ \\
\hline \multirow{3}{*}{ Adaptation Period } & 1 & 0.500 & 0.450 & 90.0 \\
\cline { 2 - 5 } & $5-11$ & 0.800 & 0.286 & 90.5 \\
\hline $\begin{array}{c}\text { Mono Digestion of } \\
\text { AWW }\end{array}$ & $12-17$ & 0.230 & 0.200 & 63.7 \\
\hline $\begin{array}{c}\text { Co-Digestion of } \\
\text { SWW + AWW }\end{array}$ & $30-42$ & 0.230 & 0.145 & 78.7 \\
\hline
\end{tabular}

Table 4:- COD result obtained at different phases. 


\section{Alkalinity Ratio (IA/PA).}

Alkalinity ratio was investigated and the distribution of alkalinity values obtained for reactor is shown in Figure 3. Volatile acids/Alkalinity ratio (IA/PA) could provide information on the stability of the reactors. For a good performing anaerobic digestion process the values should be below 0.3 while values $0.3-0.5$ show deficiencies in the operating system (Andreoli, 2007). In phase 4, which runs on single digestion of AWW, it seems buffering capacity for this type of sample recorded higher than 0.8 , indicate the reactor was unstable and vulnerable to any change in environment. If the ratio reaches values higher than 0.8 , the reactor has become acidic condition which may result to anaerobic digestion failure (Andreoli, 2007). Besides, the $\mathrm{pH}$ values during this phase also recorded reduced to values lower than 6.0.
However, during phase 5, when reactor was feeding with new feedstock the reactor performance become stable with alkalinity ratios between 0.2-0.5. Pereira et al. (2009) stated that it is possible to gain stability in the digestion system with values differ from 0.3 , due to differentiation in the composition of each effluent. This indicates that the reactors have sufficient buffering capacity for the anaerobic digestion process and less deficiencies in the digestion process. In comparison from the results obtained, the reactors have a good performance and stability in phase 5 .

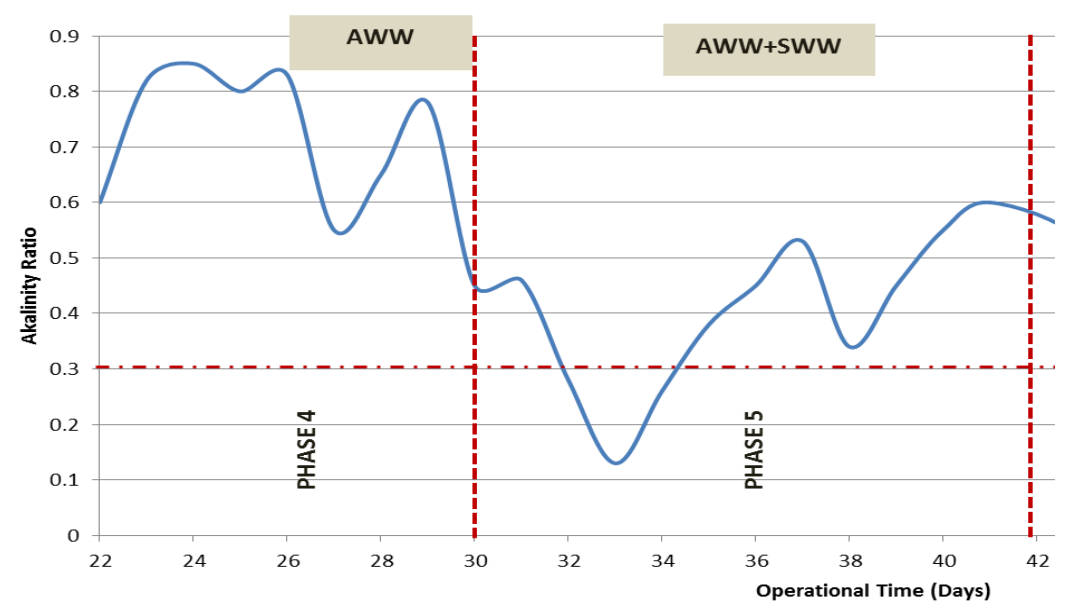

Fig 3:- Behavior of $\mathrm{pH}$ in the reactor digesting different feedstock

\section{E. Biogas Production.}

During the first occasions for single anaerobic digestion of AWW sample, the gas production decreased over the time. Gas production can be useful indicator in observing reactor suffering from toxicants. Considering to the previous study from Zayed (2000), it was assumed that the presence of heavy metal concentrations in AWW during mono digestion might have cause inhibition in the reactor performance. Accumulation of heavy metals may indicate by reduced level in gas production and biogas methane content (Yue et al., 2013). Low pH value observed in the phase also believed to yield for low optimal performance of methanogens in gas generation. In relation to the situation, COD removal were erratic with average removal during the digestion was $63.4 \%$ and gas production yield at day 29 was only $5 \mathrm{ml}$ and there was no methane achieved. These results showed that anaerobic digestion with AWW has proved difficult and the reactor was operating under unstable condition. The gas composition produced during this phase was compose of $\mathrm{N} 2$ (74.04\%), O2 (24.60) and CO2 $(1.36 \%)$. The high percentage of nitrogen in the reactor indicates that denitrification was the main biological process yield in the system during this phase (Bernet et al., 2000). Denitrification is a process in which nitrate is reduced to nitrogen gas by facultative anaerobic bacterium (Akkunna et al., 1992).
In the phase of co digestion of SWW and AWW, pH value was quite stable within the range of 6.3-6.7 with the rates of COD removal $78.7 \%$. The COD removal rate was better than single digestion. The result of biogas production increased from the beginning of co digestion until day 35 when it started declined steadily with some fluctuations before reach steady state. The methane production recorded as $24.51 \%$ for day 42 . Table 4.7 illustrated the theoretical and actual $\mathrm{CH} 4$ yield during this experiment based on COD removed. In correspondence to the COD removal rate of $86.67 \%$ the volume of methane produced during the co digestion of SWW and AWW were $0.07 \mathrm{~L}$ of $\mathrm{CH} 4$ / day.

\section{CONCLUSION}

The results of AWW digestion demonstrate that the process was operating with low biodegradation rate. The process was indicated by the decrease of biogas production, low $\mathrm{pH}$ below 6.0 and low COD removal efficiency. Final $\mathrm{pH}$ observed was drop to 5.85 during the digestion which may inhibit methanogens particularly. COD removal were erratic with average removal was $63.4 \%$ and there was no methane achieved. A poor result of anaerobic single digestion of this sample seems to be linked to heavy metal inhibition due to the presence of $\mathrm{Zn}$ and $\mathrm{Cu}$ in AWW. The reactor achieved stability in Mono Digestion of SWW 
sample with highest COD removal at $95 \%$. Co-digestion of AWW with SWW proved to improve the performance of the reactor. The nutrient content available in the SWW could promote the synergistic effect in co digestion with AWW and hence performed better than mono digestion of AWW. During this phase, the reactors have sufficient buffering capacity as showed in alkalinity ratio value of less than 0.3 . The COD removal rate was higher and better than mono digestion of AWW with highest removal achieved at steady state was $86.6 \%$. Biogas production recorded to be increased from the beginning of co digestion on day 30 until reach steady state on day 42 .

\section{REFERENCES}

[1]. Akunna, J. C., Bizeau, C., \& Moletta, R. (1992). Denitrification in anaerobic digesters: Possibilities and influence of wastewater COD/N-NOX ratio.Environmental Technology, 13(9), 825-836.

[2]. Andreoli, C. V., von Sperling, M., \& Fernandes, F. (Eds.). (2007). Sludge treatment and disposal (Vol. 6). IWA publishing.

[3]. Bernet, N., Delgenes, N., Akunna, J. C., Delgenes, J. P., \& Moletta, R. (2000). Combined anaerobicaerobic SBR for the treatment of piggery wastewater.Water Research, 34(2), 611-619.

[4]. Hartmann, H., \& Ahring, B. K. (2005). Anaerobic digestion of the organic fraction of municipal solid waste: influence of co-digestion with manure. Water research, 39(8), 1543-1552.

[5]. Haw, L. C., Salleh, E., \& Jones, P. (2006). Renewable energy policy and initiatives in Malaysia. ALAM CIPTA, International Journal on Sustainable Tropical Design Research \& Practice, 1(1), 33-40.

[6]. Idrus, S. (2007). The effect of bubble size on the Rate Of Oxygen Transfer During Aeration Process, (Master Thesis, Universiti Teknologi Mara).

[7]. Idrus, S. (2007). The effect of bubble size on the Rate Of Oxygen Transfer During Aeration Process, (Master Thesis, Universiti Teknologi Mara).

[8]. Pereira E.L, Campos C.M and Monterani F (2009). Effects of $\mathrm{pH}$, acidity and alkalinity on the microbiota activity of anaerobic sludge blanket reactor (UASB) treating pig manure effluent. v4;n3;157-168.

[9]. Shin, S. G., Han, G., Lim, J., Lee, C., \& Hwang, S. (2010). A comprehensive microbial insight into twostage anaerobic digestion of food waste-recycling wastewater. Water research, 44(17), 4838-4849.

[10]. Strik, D. P. B. T. B., Domnanovich, A. M., \& Holubar, P. (2006). A pH-based control of ammonia in biogas during anaerobic digestion of artificial pig manure and maize silage. Process Biochemistry, 41(6), 1235-1238.

[11]. Ward, A. J., Hobbs, P. J., Holliman, P. J., \& Jones, D. L. (2008). Optimisation of the anaerobic digestion of agricultural resources. Bioresource technology,99(17), 7928-7940. 